\title{
DNA BARCODING LIBRARY DATABASE OF AQUILARIA MEMBER AND GYRINOPS MEMBER
}

\author{
I Gde Adi Suryawan Wangiyana \\ Program Studi Kehutanan Universitas Pendidikan Mandalika \\ dede.consultant@gmail.com
}

\begin{abstract}
Aquilaria and Gyrinops are the primary agarwood producer on international trade. For authentication and standardization purposes, it is essential to carry DNA barcoding studies of these genera. DNA barcoding studies on plants need a database of several regions on the plant genome that could act as a barcoding marker. These DNA barcoding markers could be divided into Chloroplasts barcoding and Nuclear barcoding. Several markers have been used for DNA barcoding study of agarwood producer species, including trnL-trnF, matK, rbcL, rpoC1, ycf1 (Chloroplast barcoding), and ITS (Nuclear barcoding). This review breakdown the availability of those DNA barcoding markers on the online genebank database for Aquilaria and Gyrinops. Aquilaria genus has 12 species members, while Gyrinops genus has six species members. The sequence of region trnL-trnF is the only barcoding marker covering all 12 species members of Aquilaria and six species members of Gyrinops. Both ITS and matK have covered nine species among 12 total species members of Aquilaria. The rbcL, rpoC1, and ycf1, respectively, have covered eight, five, and four species members of Aquilaria. Most of the barcoding markers have covered three species members of Gyrinops except for ITS ( 5 species) and rpoC1 (1 species). However, Gyrinops members have no ycf1 sequence on genebank database. Based on sequence availability on the genebank database, it could be concluded that the trnL-trnF region is the most promising DNA barcoding marker for the Aquilaria and Gyrinops members especially for the phylogenetic analysis purpose.
\end{abstract}

Keywords : DNA barcoding, Aquilaria, Gyrinops

\section{PENDAHULUAN}

Kelompok Aquilaria dan Gyrinops dikenal sebagai penghasil komoditi gaharu yang merupakan hasil hutan bukan kayu bernilai ekonomis tinggi (Wangiyana dan Malik, 2018). Pengembangan industri gaharu baik dari tahap hulu sampai hilir umumnya berfokus pada spesies anggota kedua genus tersebut (Wangiyana dan Putri, 2019). Demikian pula dengan fokus riset dan pengembangan yang secara dominan mengkaji kedua genus tersebut terutama dalam hal autentifikasi spesies (Wangiyana, 2019).

Autentifikasi spesies menjadi semakin krusial bagi kelompok Aquilaria dan Gyrinops. Hal ini dikarenakan kedua kelompok ini masuk dalam CITES Apendix I dan II (Schmidt, 2011). Autentifikasi tersebut diperlukan dalam hal konservasi sekaligus penentuan kuota komoditi gaharu dari kedua genus tersebut (Lee et al., 2016a).

DNA barcoding merupakan salah satu metode autentifikasi spesies yang dapat diandalkan di era biologi molekuler saat ini (Tanaka dan Ito, 2019). DNA barcoding sekaligus dapat dijadikan sebagai metode untuk standardisasi kualitas bahan baku produk industri (Salgueiro et al., 2009). Hal ini merupakan suatu peranan yang krusial karena kualitas bahan baku menentukan kualitas produk industri yang dihasilkan (Sgamma et al., 2017).

Studi DNA barcoding memerlukan pemilihan marker yang digunakan sebagai bahan utama dalam klasifikasi secara molekuler (De Mattia et al., 2010). Marker molekular tersebut berupa region dalam DNA genom yang dapat diamplifikasi oleh primer universal. Total terdapat 17 region DNA barcoding yang dilaporkan pada tanaman terutama tanaman berkhasiat medis (Chase and Fay, 2009). Marker DNA barcoding untuk tanaman yang disarankan oleh Concortium for the Barcode of Life-Plant Working Group (CBOL) adalah yang memiliki nilai efisiensi diskriminasi sebesar $72 \%$. Oleh karena itulah pemilihan marker untuk DNA 
barcoding merupakan hal yang penting untuk dilaukan (CBOL Plant Working Group, 2009).

Marker DNA barcoding yang umum digunakan pada spesies penghasil komoditi gaharu diantaranya adalah $m a t \mathrm{~K}, r b c \mathrm{~L}, r p o \mathrm{C} 1$, trnL-trnF, dan ITS (Lee et al., 2016a). Penelusuran database marker DNA barcoding tersbut merupakan hal yang esensial untuk menunjang penyediaan data identifikasi spesies penghasil gaharu yang autentik. Oleh karena itu, artikel ini bertujuan untuk melakukan review terhadap database marker DNA barcoding spesies penghasil gaharu bada gene bank yang terintegrasi secara daring.

\section{JENIS MARKER DNA BARCODE}

Secara umum Jenis DNA barcode pada tanaman dapat dibedakan menjadi Nuclear barcode dan chloroplast barcode. Nuclear barcode umumnya berisi non-coding region. Sementara itu Chloroplast barcode dapat dibedakan menjadi coding region dan noncoding region (Enan, 2015). Untuk lebih jelasnya dapat dilihat pada gambar 1 .

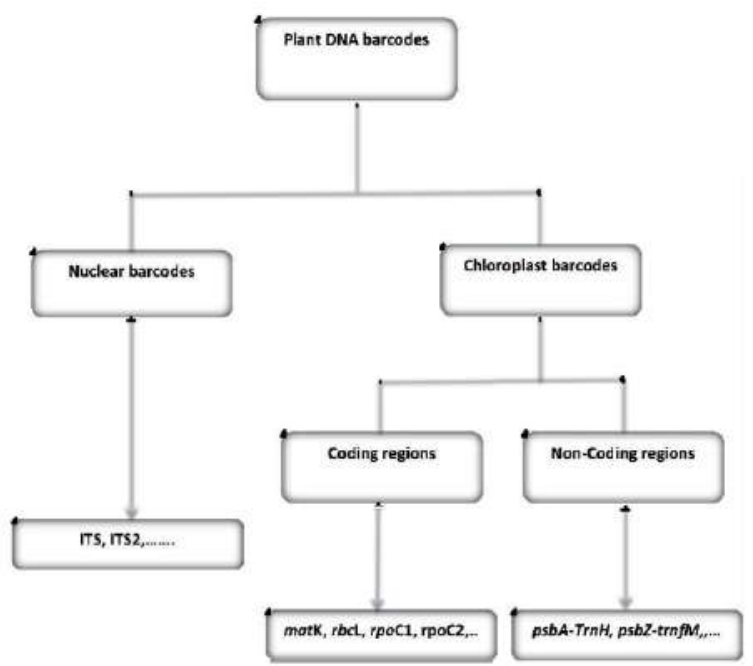

Gambar 1. Tipe marker DNA barcode pada tanaman (Enan, 2015)

Hal krusial yang harus diperhatikan dalam menganalisis marker DNA barcode adalah menentukan primer yang tepat. Primer yang tepat akan mengamplifikasi region barcode seperti yang diharapkan. Beberapa primer universal untuk amplifikasi region chloroplast barcode telah berhasil dipetakan (Demesure et al., 1995). Sementara itu, untuk Nuclear barcode pada tanaman umumnya terdiri dari beberapa copy lokus yang sangat variatif sehingga sulit untuk dipetakan pembuatan primer universalnya
(Yu et al., 2011). Beberapa contoh primer untuk region DNA barcoding disajikan pada tabel 1 .

Tabel 1. Referensi desain primer untuk amplifikasi sekuen DNA barcoding

\begin{tabular}{|c|c|c|c|}
\hline Region & Primer & Sekuen $\left(5^{\prime} \rightarrow 3^{\prime}\right)$ & Referensi \\
\hline \multirow[t]{2}{*}{ ITS } & ITS5_F & $\begin{array}{l}\text { GGAAGTAAAAGTCGTAAC } \\
\text { AAGG }\end{array}$ & $\begin{array}{l}\text { Cleverdon et } \\
\text { al., } 2018\end{array}$ \\
\hline & ITS4_R & $\begin{array}{l}\text { TCCTCCGCTTATTGATATG } \\
\mathrm{C}\end{array}$ & \\
\hline \multirow[t]{2}{*}{ matK } & 3F-KIM f & $\begin{array}{l}\text { CGTACAGTACTTTTGTGTT } \\
\text { TACGAG }\end{array}$ & $\begin{array}{c}\text { White et al., } \\
1990\end{array}$ \\
\hline & 1R-KIM r & $\begin{array}{l}\text { ACCCAGTCCATCTGGAAA } \\
\text { TCTTGGTTC }\end{array}$ & \\
\hline \multirow[t]{2}{*}{ rbcL } & rbcL-aF & $\begin{array}{l}\text { ATGTCACCACAAACAGAG } \\
\text { ACTAAAGC }\end{array}$ & $\begin{array}{c}\text { Jeanson et al., } \\
2011\end{array}$ \\
\hline & rbcL-aR & $\begin{array}{l}\text { CTTCTGCTACAAATAAGA } \\
\text { ATCGATCTC }\end{array}$ & \\
\hline \multirow[t]{2}{*}{ rpoC1 } & $2 \mathrm{~F}$ & $\begin{array}{l}\text { GGCAAAGAGGGAAGATT } \\
\text { TCG }\end{array}$ & $\begin{array}{l}\text { Levin et al., } \\
2003\end{array}$ \\
\hline & $4 \mathrm{R}$ & $\begin{array}{l}\text { CCATAAGCATATCTTGAG } \\
\text { TTGG }\end{array}$ & \\
\hline \multirow[t]{2}{*}{$y c f 1$} & $y c f 1 b F$ & $\begin{array}{l}\text { TCTCGACGAAAATCAGAT } \\
\text { TGTTGTGAAT }\end{array}$ & $\begin{array}{l}\text { Sass et al., } \\
\quad 2007\end{array}$ \\
\hline & ycflbR & $\begin{array}{l}\text { ATACATGTCAAAGTGATG } \\
\text { GAAAA }\end{array}$ & \\
\hline \multirow[t]{2}{*}{$\begin{array}{l}\operatorname{trnL}- \\
\operatorname{trnF}\end{array}$} & $\mathrm{e}$ & $\begin{array}{l}\text { GGTTCAAGTCCCTCTATC } \\
\text { CC }\end{array}$ & $\begin{array}{l}\text { Dong et al., } \\
2015\end{array}$ \\
\hline & $\mathrm{f}$ & $\begin{array}{l}\text { ATTTGAACTGGTGACACG } \\
\text { AG }\end{array}$ & \\
\hline
\end{tabular}

\section{BARCODE REGION TRNL-TRNF}

TrnL-trnF region merupakan salah satu kelompok chloroplast barcode. Region ini terletak pada large single-copy region dari genome chloroplast. Region ini terdiri dari gen trnL, grup intron 1 dan trnL-trnF intergenic spacer (Hao et al., 2009). Lokasi annealing primer untuk region trnL-trnF dapat dilihat pada gambar 2.

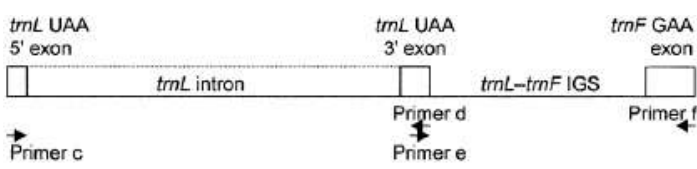

Gambar 2. Lokasi Anealing primer untuk region trnL-trnF

Sekuen trnL-trnF merupakan marker DNA barcoding yang umum digunakan dalam analisis filogenetik species penghasil gaharu dari kelompok Aquilaria dan Gyrinops (Wangiyana, 2016). Sekuen trnL-trnF seluruh anggota genus Aquilaria yang berjumlah 12 spesies dan genus Gyrinops yang berjumlah 6 species tercatat lengkap pada database genebank NCBI (tabel 2).

Berdasarkan data se kuen pada tabel 2, rata - rata sekuen trnL-trnF pada database NCBI memiliki ukuran antara 447 bp - 582 bp (Farah et al., 2018; Eurlings \& Gravendeel, 2003). Sementara itu sekuen - sekuen tersebut tergolong cukup lengkap yang dikoleksi dari 
berbagai negara penghasil gaharu di Asia seperti Indonesia, Thailand, Malaysia (Asia Tenggara), China (Asia Timur) dan India (Asia Selatan). Hal ini kembali menegaskan bahwa sekuen ini merupakan DNA barcoding yang ideal untuk kelompok Aquilaria dan Gyrinops (Wangiyana, 2016).

Tabel 2. Database sekuen trnL-trnF

\begin{tabular}{|c|c|c|c|c|c|}
\hline No & Spesies & $\begin{array}{l}\text { Assesion } \\
\text { Number }\end{array}$ & BP & $\begin{array}{l}\text { Asal } \\
\text { Spesimen } \\
\end{array}$ & Referensi \\
\hline \multicolumn{6}{|c|}{ Genus Aquilaria } \\
\hline 1 & A. subintegra & KU244049 & 499 & Thailand & $\begin{array}{l}\text { Lee et al., } \\
2016 \mathrm{a}\end{array}$ \\
\hline 2 & A. rostrata & KT364475 & 500 & Malaysia & $\begin{array}{l}\text { Lee \& } \\
\text { Mohamed, } \\
2016\end{array}$ \\
\hline 3 & A. yunnanensis & MH603329 & 462 & China & $\begin{array}{l}\text { Feng et al., } \\
2018\end{array}$ \\
\hline 4 & A. sinensis & KF018041 & 471 & China & $\begin{array}{l}\text { Jiao et al., } \\
2013\end{array}$ \\
\hline 5 & A. rugosa & MF443430 & 463 & Thailand & $\begin{array}{l}\text { Farah et al., } \\
2018\end{array}$ \\
\hline 6 & A. cumingiana & KT726320 & 499 & Indonesia & $\begin{array}{l}\text { Lee et al., } \\
2016 b\end{array}$ \\
\hline 7 & A. agallochum & MF443428 & 447 & India & $\begin{array}{l}\text { Farah et al., } \\
2018\end{array}$ \\
\hline 8 & A. microcarpa & KU244042 & 498 & Indonesia & $\begin{array}{l}\text { Lee et al., } \\
2016 \mathrm{a}\end{array}$ \\
\hline 9 & A. urdanetensis & AY216750 & 582 & Indonesia & Eurlings \& \\
\hline 10 & A. parvifolia & AY216748 & 581 & Indonesia & Gravendeel, \\
\hline 11 & A. khasiana & AY216744 & 570 & Indonesia & 2003 \\
\hline 12 & A. hirta & KT364472 & 497 & Malaysia & $\begin{array}{l}\text { Lee \& } \\
\text { Mohamed, } \\
2016 \\
\end{array}$ \\
\hline \multicolumn{6}{|c|}{ Genus Gyrinops } \\
\hline 1 & G. versteegii & KU244054 & 500 & Indonesia & $\begin{array}{l}\text { Lee et al., } \\
2016 a\end{array}$ \\
\hline 2 & G. walla & AY216758 & 544 & Indonesia & Eurlings \& \\
\hline 3 & G. salicifolia & AY216757 & 556 & Indonesia & Gravendeel, \\
\hline 4 & G. ledermannii & AY216755 & 563 & Indonesia & 2003 \\
\hline 5 & G. caudata & KT726323 & 500 & Indonesia & Lee et al. \\
\hline 6 & G. moluccana & KT726325 & 498 & Indonesia & $2016 \mathrm{~b}$ \\
\hline
\end{tabular}

\section{BARCODE REGION ITS}

Internal Transcribe Spacer (ITS) merupakan region yang mengapit 3 subunit dari RNA yaitu 18 SRNA, 5,8vSRNA dan 28S RNA. Total terdapat 4 region ITS diantara subunit RNA tersebut yaitu ITS1, ITS 2, ITS 3 dan ITS 4 (Gambar 3). Diantara region ITS lainnya, ITS 1-ITS2 yang mengapit region 5,8S RNA dengan panjang sekuen 400 sampai 1000 bp merupakan marker yang paling umum digunakan dalam studi DNA barcoding (Alvarez and Wandel, 2003).

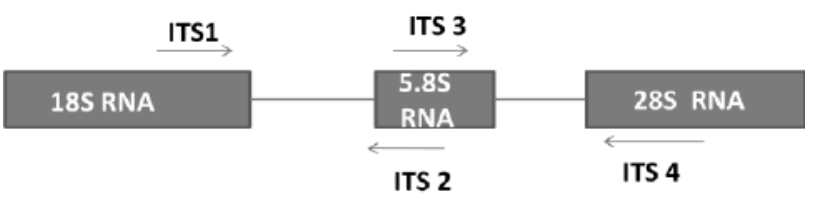

Gambar 3. Susunan ITS diantara Subunit RNA (Sahid, 2004)
Tabel 3. Database sekuen ITS1-ITS2

\begin{tabular}{|c|c|c|c|c|}
\hline Spesies & $\begin{array}{l}\text { Assesion } \\
\text { Number }\end{array}$ & BP & $\begin{array}{l}\text { Asal } \\
\text { Spesimen }\end{array}$ & Referensi \\
\hline \multicolumn{5}{|c|}{ Genus Aquilaria } \\
\hline 1 A. subintegra & MH594316 & 673 & Malaysia & $\begin{array}{l}\text { Feng et al., } \\
2018\end{array}$ \\
\hline 2 A. rostrata & KT364483 & 682 & Malaysia & $\begin{array}{l}\text { Lee and } \\
\text { Mohamed, } \\
2016\end{array}$ \\
\hline $3 A \cdot y u$ & MH594327 & 673 & China & $\begin{array}{lll}\text { Feng } & \text { et al., } \\
2018 & & \\
\end{array}$ \\
\hline 4 A. sinensis & EF645836 & 680 & China & $\begin{array}{l}\text { Shen, et al., } \\
2007\end{array}$ \\
\hline 5 A. rugosa & MH134145 & 789 & Thailand & $\begin{array}{l}\text { Farah et al., } \\
2018\end{array}$ \\
\hline $6 A . c$ & KT779117 & 739 & Ind & $\begin{array}{l}\text { Lee et al., } \\
2016 \mathrm{~b}\end{array}$ \\
\hline 7 A. agallochum & MH134137 & 789 & India & $\begin{array}{l}\text { Farah et al., } \\
2018\end{array}$ \\
\hline 8 A. microcarpa & KU244094 & 685 & Indo & $\begin{array}{l}\text { Lee et al., } \\
2016 \mathrm{a}\end{array}$ \\
\hline 9 A. hi & KX424702 & 673 & Malc & \\
\hline \multicolumn{5}{|c|}{ Genus Gyrinops } \\
\hline 1 G.ver & KU244106 & 683 & Indonesia & $\begin{array}{l}\text { Lee et al., } \\
2016 a\end{array}$ \\
\hline 2 G. walla & MH134151 & 786 & Sri Lanka & $\begin{array}{l}\text { Farah et al., } \\
2018\end{array}$ \\
\hline 3 G. ledermannii & KT779120 & 739 & Indonesia & Lee et al., \\
\hline 4 G. caudata & KT779119 & 739 & Indo & $2016 \mathrm{~b}$ \\
\hline 5 G. moluccana & KT779121 & 739 & Indonesia & \\
\hline
\end{tabular}

Berdasarkan penelusuran database genebank NCBI, terdapat 7 anggota genus Aquilaria dan 5 anggota genus Gyrinops yang telah tercatat memiliki data sekuen ITS. Sekuen ITS tersebut memiliki ukuran bervariasi antara 673 bp - 789 bp. Rata - rata ukuran sekuen yang lebih panjang dibandingkan trnL-trnF. Sekuen tersebut juga diperoleh dari berbagai negara Asia penghasil gaharu diantaranya: Indonesia, Malaysia, Thailand (Asia Tenggara), China (Timur), India dan Sri lanka (Asia Selatan). Hal ini menunjukkan sekuen ini cukup layak untuk dijadikan marker DNA barcoding (Feng et al., 2018; Lee and Mohamed, 2016; Farah et al., 2018; Lee et al., 2016b; Li et al., 2017).

\section{BARCODE REGION RPOC1}

Region rpoC1 bersama dengan rpoC2, rpoA dan rpoB mengkode subunit Plastid RNA polymerase (PEP). Secara lebih spesifik rpoC1 mengkode subunit $\beta$ dari PEP (Serino and Maliga, 1998). Region ini memiliki ukuran pada rentang $400 \mathrm{bp}-1100 \mathrm{bp}$ dan dapat dijadikan sebagai salah satu marker DNA barcoding yang potensial (Downie et al., 1998). Skema amplifikasi region rpoC dapat dilihat pada gambar 3 


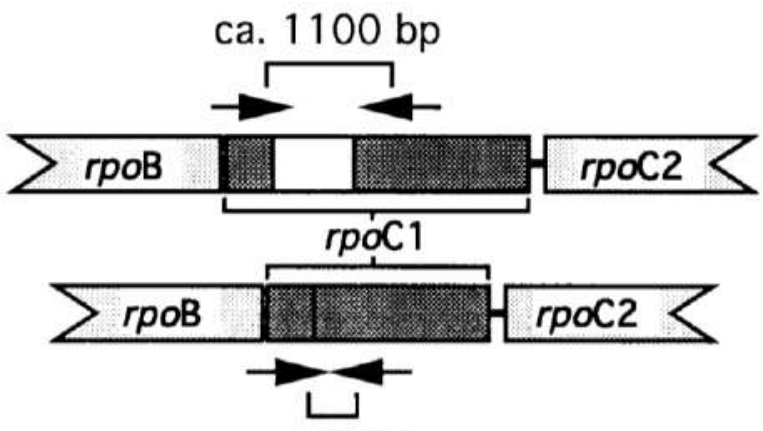

ca. $400 \mathrm{bp}$

Gambar 3. Skema amplifikasi region rpoC1 (Downie et al., 1998)

Tabel 4. Database sekuen rpoC1

\begin{tabular}{|c|c|c|c|c|}
\hline Spesies & $\begin{array}{l}\text { Assesion } \\
\text { Number }\end{array}$ & BP & $\begin{array}{l}\text { Asal } \\
\text { Spesimen }\end{array}$ & Referensi \\
\hline \multicolumn{5}{|c|}{ Genus Aquilaria } \\
\hline 1 A. subintegra & LC383851 & 529 & Thailand & $\begin{array}{l}\text { Thitikornpon } \\
\text { et al., } 2018\end{array}$ \\
\hline 2 A. yunnanensis & KU244181 & 529 & China & Lee \\
\hline 3 A. sinensis & KU244178 & 529 & China & $2016 a$ \\
\hline 4 A. microcarpa & KU244172 & 529 & Indonesia & \\
\hline $5 \quad$ A. hirta & KU244166 & 529 & Malaysia & \\
\hline \multicolumn{5}{|c|}{ Genus Gyrinops } \\
\hline 1 G. versteegii & KU244184 & 529 & Indonesia & $\begin{array}{l}\text { Lee et al., } \\
2016 \mathrm{a}\end{array}$ \\
\hline
\end{tabular}

Berdasarkan penelusuran di database genebank NCBI, terdapat 5 spesies genus Aquilaria dan hanya satu spesies genus Gyrinops yang memiliki data sekuen rpoC1. Sekuen rpoC1 pada database tersebut rata - rata memiliki ukuran 529 bp. Ukuran yang relatif lebih pendek dibandingkan marker DNA barcoding pada umumnya. Meskipun demikian, sekuen tersebut relatif heterogen karena berasal dari berbagai negara penghasil gaharu meliputi: Indonesia, Malaysia, Thailand (Asia Tenggara) dan China (Asia Timur) (Thitikornpon et al., 2018; Lee et al., 2016a).

\section{BARCODE REGION MATK}

Region Maturase K (matK) merupakan salah satu region pada kloroplast yang memiliki level diskriminasi tinggi diantara kelompok Angiospermae (Fazekas et al., 2008). Keunggulan region ini sebagai marker DNA barcoding adalah memiliki kemampuan untuk mengidentifikasi variasi, mudah diamplifikasi, disekuensing serta analissi alignment. Hal ini lah yang menjadikannya layak diusulkan sebagai universal DNA barcoding terutama untuk tanaman berbunga (Lahaye et al., 2008). Secara structural, region matK diapit oleh dua region trnK yang dipisahkan oleh trnK intron (gambar 4)
Tabel 5. Database sekuen matK

\begin{tabular}{|c|c|c|c|c|}
\hline Spesies & $\begin{array}{l}\text { Assesion } \\
\text { Number }\end{array}$ & BP & $\begin{array}{l}\text { Asal } \\
\text { Spesimen }\end{array}$ & Referensi \\
\hline \multicolumn{5}{|c|}{ Genus Aquilaria } \\
\hline 1 A. subintegra & LC383999 & 818 & Thailand & $\begin{array}{l}\text { Thitikornpon } \\
\text { et al., } 2018\end{array}$ \\
\hline 2 A.ro & MF443401 & 834 & Malaysia & $\begin{array}{l}\text { Farah et al., } \\
2018\end{array}$ \\
\hline 3 A. yunnanensis & KR530387 & 747 & China & $\begin{array}{l}\text { Huang et al., } \\
2015\end{array}$ \\
\hline$\overline{4 \text { A.s }}$ & HQ415244 & 805 & China & $\begin{array}{l}\begin{array}{l}\text { Pei et al., } \\
2011\end{array} \\
\end{array}$ \\
\hline 5 A. rugosa & MF443402 & 834 & Thailand & Farah et al., \\
\hline 6 A. cumingiana & MF443400 & 834 & Indonesia & 2018 \\
\hline 7 A. agallochum & MF443398 & 834 & India & \\
\hline 8 A. microcarpa & LC467528 & 801 & Indonesia & $\begin{array}{ll}\text { Tanaka } & \text { and } \\
\text { Ito, } 2019 & \\
\end{array}$ \\
\hline 9 A. hirta & KY927321 & 886 & Malaysia & Li et al., 2017 \\
\hline \multicolumn{5}{|c|}{ Genus Gyrinops } \\
\hline 1 G. versteegii & KU244210 & 886 & Indonesia & $\begin{array}{l}\text { Lee et al., } \\
2016 \mathrm{a}\end{array}$ \\
\hline 2 G. walla & MF443404 & 834 & Sri Lanka & $\begin{array}{l}\text { Farah et al., } \\
2018\end{array}$ \\
\hline 3 G. caudata & MF443403 & 834 & Indonesia & $\begin{array}{l}\text { Farah et al., } \\
2018\end{array}$ \\
\hline
\end{tabular}

Berdasarkan penelusuran database di genebank NCBI, ditemukan bahwa sebanyak 9 spesies genus Aquilaria dan 3 spesies genus Gyrinops tercatat memiliki sekuen matK. Sekuen tersebut berasal dari berbagai negara penghasil gaharu seperti: Indonesia, Malaysia, Thailand (Asia Tenggara), India, Sri Lanka (Asia Selatan) dan China (Asia Timur). Sekuen matK merupakan salah satu marker DNA barcoding yang memiliki ukuran besar dengan rentang 747 bp - 886 bp (Thitikompon et al., 2018; Farah et al., 2018; Huang et al., 2015; Pei et al., 2011; Lee et al., 2016a).

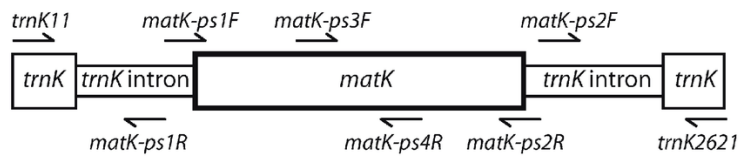

Gambar 4. Diagram sekuen matK gen plastida (Kim et al., 2017)

\section{BARCODE REGION RBCL}

Region Subunit besar Ribulose 1,5biphosphate carboxylase oxygenese (rbcL) merupakan salah satu coding region kloroplast yang memiliki amplification rate tinggi. Dengan tingkat keberhasilan amplifikasi tinggi sekuen region ini mudah untuk diisolasi sehingga menjadikannya sebagai marker DNA barcoding yang potensia (Blaxter, 2004). Struktur region rbcL dapat dilihat pada gambar 5 . 


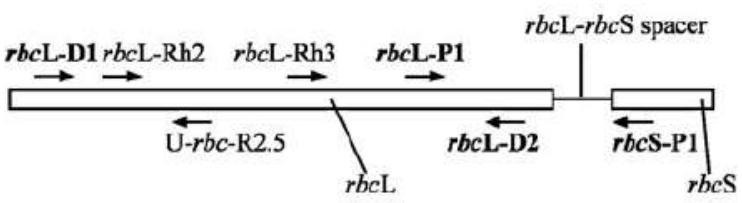

Gambar 5. Sekuen gene pengkode enzim rbcL pada kloroplast (Win et al., 2008)

Tabel 6. Database sekuen rbcL

\begin{tabular}{|c|c|c|c|c|c|}
\hline & Spesies & $\begin{array}{l}\text { Assesion } \\
\text { Number }\end{array}$ & $\mathrm{BP}$ & $\begin{array}{l}\text { Asal } \\
\text { Spesimen }\end{array}$ & Referensi \\
\hline \multicolumn{6}{|c|}{ Genus Aquilaria } \\
\hline$\overline{1}$ & A. $s u$ & MH603257 & 553 & Malaysia & $\begin{array}{l}\text { Feng et al., } \\
2018\end{array}$ \\
\hline & A. ros & MF443408 & 617 & Malaysia & $\begin{array}{l}\text { Farah et al., } \\
2018\end{array}$ \\
\hline 3 & A. yunnanensis & KR528754 & 618 & China & $\begin{array}{l}\text { Huang et } \\
\text { al., 2015 }\end{array}$ \\
\hline 4 & A. sinensis & GQ436620 & 703 & $\mathrm{Ch}$ & $\begin{array}{l}\text { Chen et al., } \\
2010\end{array}$ \\
\hline & A. rugosa & MF443409 & 617 & Thailand & Farah et al., \\
\hline & A. cumingiana & MF443407 & 617 & Indonesia & 201 \\
\hline 7 & A. microcarpa & KX424689 & 623 & Malaysia & Lee et al., \\
\hline 8 & A. hirta & KX424688 & 623 & Malaysia & \\
\hline \multicolumn{6}{|c|}{ Genus Gyrinops } \\
\hline 1 & G. versteegii & KU244236 & 670 & Indonesia & \begin{tabular}{|l} 
Lee et al., \\
$2016 \mathrm{a}$
\end{tabular} \\
\hline 2 & G. walla & MF443411 & 617 & Sri Lanka & Farah et al., \\
\hline & G. caudata & MF443410 & 617 & Indonesia & 2018 \\
\hline
\end{tabular}

Berdasarkan penelusuran database di genebank NCBI, 8 spesies anggota genus Aquilaria dan 3 spesies anggota genus Gyrinops tercatat memiliki sekuen rbcL. Sekuen tersebut diisolasi dari berbagai negara penghasil gaharu yaitu: Indonesia, Malaysia, Thailand (Asia Tenggara), Sri Lanka (Asia Selatan) dan China (Asia Timur). Rata - rata sekuen rbcL pada database NCBI memiliki ukuran menyerupai sekuen trnL-trnF yaitu antara 533 bp - 703 bp (Feng et al., 2018; Farah et al., 2018; Chen et al., 2010; Lee et al., 2016c)

\section{BARCODE REGION YCF1}

Region ycf1 merupakan region pada kloroplast yang memili variabailitas tinggi. Region ini memiliki resolusi tinggi ketika digunakan sebagai marker DNA barcoding pada level spesies. Region sekaligus dikatakan sebagai marker DNA barcoding paling menjanjikan untuk tanaman terrestrial (Dong et al., 2015). Secara structural Skema gen ycf1 merupakan sekuen yang berada pada inverted repeat region. Bagian dari gen ycf1 berinkorporasi dengan inverted repeat region dan juga region yang bersifat homologus. Bagian ini ditandai dengan region warna hitam pada gambar 6 .

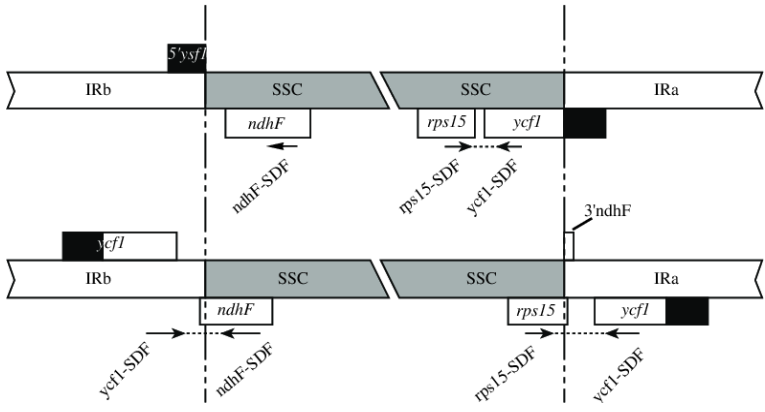

Meskipun merupakan marker DNA barcoding yang potensial untuk tanaman terrestrial, namun berdasarkan penelusuran database genebank NCBI, sekuen ycf1 dapat dikatakan kurang mampu mendukung keperluan barcoding tanaman penghasil gaharu. Tercatat hanya ada 4 spesies anggota Aquilaria yang memiliki sekuen ycf1 pada database NCBI. Bahkan tidak ditemukan sama sekali sekuen ycf1 untuk anggota spesies Gyrinops. Meskipun demikian, sekuen ycf1 dari genus Aquilaria rata - rata memiliki ukuran 919 bp. Ukran relatif besar dibandingkan marker DNA barcoding lainnya (Li et al., 2017)

\begin{tabular}{|c|c|c|c|c|}
\hline Spesies & $\begin{array}{l}\text { Assesion } \\
\text { Number }\end{array}$ & $\begin{array}{l}\text { Ukuran } \\
\text { (bp) }\end{array}$ & $\begin{array}{l}\text { Asal } \\
\text { Spesimen }\end{array}$ & Referensi \\
\hline \multicolumn{5}{|c|}{ Genus Aquilaria } \\
\hline 1 A. subintegra & KY927354 & 919 & Indonesia & $\mathrm{Li}$ et \\
\hline 2 A. yunnanensis & KY927384 & 919 & China & 2017 \\
\hline 3 A. sinensis & KY927380 & 919 & China & \\
\hline 4 A. hirta & KY927365 & 919 & Malaysia & \\
\hline
\end{tabular}

Database DNA barcoding merupakan hal yang esensial karena dapat digunakan dalam berbagai hal. DNA barcoding dapat diguanakan untuk keperluan autentifikasi spesies tanaman (Narayana \& Johnson, 2019), Standardizati mutu produk tanaman herbal (Zahra et al., 2016) dan studi taksonomi terutama untuk analisis filogenetik (Kreuzer et al., 2019).

Studi DNA barcoding pada spesies tanaman penghasil gaharu sebaiknya menggunakan marker DNA barcoding yang ideal. Ketersediaan database online dari sekuen DNA barcoding tersebut merupakan salah satu parameter ideal dalam melakukan analisis, terutama untuk keperluan sistematika. Jumah sekuen yang ideal mampu menjamin analisis filogenetik dapat dilakukan dengan lebih baik (Wangiyana, 2016).

\section{KESIMPULAN}

Berdasarkan ketersediaan sekuen pada database genebank, region trnL-trnF merupakan region terlengkap yang memiliki sekuen seluruh 
anggota genus Aquilaria dan seluruh anggota genus Gyrinops sehingga ideal digunakan sebagai DNA barcoding marker untuk keperluan analisis filogenetik.

\section{SARAN}

Database sekuen region DNA barcoding hanya digunakan sebatas untuk menilai seberapa lengkap suatu marker dapat menganalisis anggota kelompok suatu takson. Data tersebut tidak mencerminkan kemampuan diskriminasi dari marker tersebut sehingga diperlukan uji lanjut untuk mengetahui hal tersebut.

\section{DAFTAR PUSTAKA}

Alvarez, I. and Wendel, J. F., 2003. Ribosomal ITS sequences and plant phylogenetic inference. Molecular Phylogenetics and Evolution. 29: 417 - 432.

Blaxter, M. L., 2004. The promise of a DNA taxonomy. Philosophical Transactions of the Royal Society of London, Series B: Biological Science. 359: 669 - 679.

CBOL Plant Working Group, 2009. A DNA barcode for land plants. Proceedings of the national academi of sciences of the United States of America. 106: 1279-12797.

Chase, M. V. And Fay, M. F. 2009. Barcoding of plants and fungi. Science. 325: 682-683.

Chen, S., Yao, H., Han, J., Liu, C., Song, J., Shi, L., Zhu, Y., Ma, X., Gao, T., Pang, X., Luo, K., Li, Y., Li, X., Jia, X., Lin, Y., Leon, C. 2010. Validation of the ITS2 region as a novel DNA barcode for identifying medicinal plant species. PLoS One 5 (1): e8613.

Cleverdon, R., Elhalaby, Y., McAlpine, M. D., Gittings, W., Ward, W. E. 2018. Total Polyphenol Content and Antioxidant Capacity of Tea Bags: Comparison of Black, Green, Red Rooibos, Chamomile and Peppermint over Different Steep Times. Beverages. 4(15): 1-13.

De Mattia, F., Bruni, I., Galimberti, A., Cattaneo, F., Casiraghi, M., Labra, M. 2010. A comparative study of differnet DNA barcoding markers for the identification of some members of Lamiacaea. Food Research International. 44 (3): $693-702$.

Demesure, B., Sodzi, N., Petit, R. J., 1995. A Set universal primers for amplification of polymorphic noncoding regions of mitochondrial and chloroplast DNA in plants. Molecular Evolution. 4: 129-131

Dong, W., Xu, C., Li, C., Sun, J., Zuo, Y., Shi, S. 2015. Ycf1, the most promising plastid DNA barcode of land plants. Sci Rep. 2015 (5): 8348

Dong, W., Xu, C., Li, C., Sun, J., Zuo, Y., Shi, S., Cheng, T., Guo, J., Zhou, S. 2015. ycf1, the most promising plastid DNA barcode of land plants. Science Report. 5: 8358.

Downie, S. R., Katz-Downie, D. S., Rogers, E. J., Zujewski, H. L., Small, E. 1998. Multiple independent losses of the plastid rpo $\mathrm{C} 1$ intron in Medicago (Fabaceae) as inferred from phylogenetic analyses of nuclear ribosomal DNA internal transcribed spacer sequences. Canadian Journal of Botany. 76 (5): $791-803$.

Enan, M. R., 2015. Molecular markers for plants DNA barcoding. In: Plant DNA barcoding and Phylogenetics. Ali, M. A., Al-Hemid, F (ed.). Lambert Academic Publishing. Germany.

Eurlings, M. C. M. and Gravendeel, B. 2003. Identification of Gaharu dry wood samples using trnL-trnF polymorphisms. https://www.ncbi.nlm.nih.gov. Diakses 10 Desember 2020.

Farah, A. H., Lee, S. Y., Gao, Z., Yao, T. L., Madon, M., and Mohamed, R., 2018. Genome Size, Molecular Phylogeny, and Evolutionary History of theTribe Aquilarieae (Thymelaeaceae), the Natural Source of Agarwood. Front Plant Sci, 9: 712

Fazekas, A. J., Burgess, K. S., Kesankurti, P. R., Graham, S. W., Newmaster, S. G. Husband, B. C., Percy, D. M., Hajibabei, M., Barrett, S. C. H. 2008. Multiple multilocus DNA barcodes from the plastid genome discriminate plants species equally well. PloS ONE, 3: e2802

Feng, T., Li, Q., Wang, Y., Qiu, S., He, M., Zhang, W., Dong, J. and, Zhu, S. 2018. Phylogenetic analysis of Aquilaria Lam. (Thymelaeaceae) based on DNA barcoding. Holzforschung 73 (6): 517-524

Feng,T., Li,Q., Wang, Y., Qiu, S., He, M., Zhang, W., Dong, J., Zhu, S. 2018. The phylogenetic analysis of Aquilaria Lam. (Thymelaesceae) based on DNA barcoding. https://www.ncbi.nlm.nih.gov. Diakses 10 Desember 2020. 
Hao, D. C., Huang, B. L., Chen, S. L., Mu, J. 2009. Evolution of the chloroplast trnLtrnF region in the gymnosperm lineages Taxaceae and Cephalotaxaceae. Biochem Genet. 47 (5-6): $351-369$.

Holt, S. D.S., Horova, L., Bures, P., 2004. Indel patterns of the plastid DNA trnL-F region within the genus Poa (Poaceae). Journal of Plant Research. 117 (5): 393 - 407

Huang, X. C., Ci, X. Q., Conran, J. G., Li, J. 2015. Application of DNA Barcodes in Asian Tropical Trees - A Case Study from Xishuangbanna Nature Reserve, Southwest China. PLos ONE, 10 (6).

Jeanson, M. L., Labat, J. N., Little, D. P. 2011. DNA barcoding: a new tool for palm taxonomist.Ann Bot. 2011 (108): 1445 1451

Jiao, L., Yin, Y., Cheng, Y., Jiang, X. 2013. DNA barcoding for identification of the endangered species Aquilaria sinensis: comparison of data from heated or aged wood sample. Holzforschung, 68 (4): 487 494

Kim, S. T., Donoghue, M. J., Sultan, S. E. 2017. On the resurrection of Persicaria puritanorum (Polygonaceae). Phytotaxa, 308 (1): 20.

Kreuzer, M., Howard, C., Adhikari, B., Pendry, C. A., Hawkins, J. A. 2019. Phylogenomic Approaches to DNA Barcoding of Herbal Medicines: Developing Clade-Specific Diagnostic Characters for Berberis. Front. Plant. Sci. 10:586.

Lahaye, R., Van Der Bank, M., Bogarin, D., Warner, J., Pupulin, F., Gigot, G., Maurin, O., Duthoit, S., Barraclough, T. G., Savolainen, V. 2008.

Lee, S. L., Zakaria, N. F., Tnah, L. H., Ng, C. H., Ng, K. K. S., Lee,C.T. 2016c. DNA Databases of a CITES listed species Aquilaria malaccensis (Thymelaeaceae) as tracking tools for forensic identification and chain -of-custody certification. https://www.ncbi.nlm.nih.gov. Diakses 10 Desember 2020.

Lee, S. Y., Ng, W. L., Mahat, M. N., Nazre, M., Mohamed, R. 2016a. DNA barcoding of the endangered Aquilaria (Thymelaeaceae) and its application in species authentication of agarwood products traded in the market. PLoS ONE. 11 (4): 1-21

Lee, S., Y. and Mohamed, R. 2016a. Rediscovery of Aquilaria rostrata (Thymelaeaceae), a species thought to be extinct, and notes on Aquilaria conservation in Peninsular Malaysia. Blumea, 61: 13-19

Lee, S.Y., Mohamed, R., Turjaman, M. 2016b. Phylogenetic Relatedness of Several Agarwood-Producing Taxa (Thymelaeaceae) from Indonesia. Tropical Life Science Research. 29 (2): 13 - 28.

Levin, R. A., Wagner, W. L., Hoch, P. C., Nepokroeff, M., Pries, J. C., Zimmer, E. A. 2003. Family-level relationship of Onagraceae based on chloroplast rbcL and ndhF data. Ann J Bot. 2003 (90): 107 115.

Li,Q., Yan, H., Lin, D., Wang, Y., Huang, Z., He, M., Zhang, W., Gao, X., Zhu, S., 2017. The identification of Aquilaria spp. at species level by DNA barcoding. https://www.ncbi.nlm.nih.gov. Diakses 10 Desember 2020.

Logacheva, M., Penin, A. A., Valiejo-Roman, C. M., Antonov, A. S., 2009. Structure and evolution of junctions between inverted repeat and small single copy regions of chloroplast genome in non-core Caryophyllales. Molecular Biology. 43 (5): $757-765$.

Narayana, D. B. and Johnson, S. T. 2019. DNA barcoding in authentication of herbal raw materials, extracts and dietary supplements: a perspective. Plant Biotechnology Reports. 13 (2019): $201-210$.

Pei, N., Lian, J. Y., Erickson, D. L., Swenson, N. G., Kress,W .J., Ye, W. H., Ge, X. J., 2011. Exploring tree-habitat associations in a Chinese subtropical forest plot using a molecular phylogeny generated from DNA barcode loci. PLoS One, 6 (6).

Sahid, M., 2014. Phylogenetic relationship of Trichoderma asperellum Tasp/8940 using Internal Transcribed Spacer (ITS) sequences. International Journal of Advanced Research . 2 (3): 979 - 986.

Salguerio, L., Martins, A. P., Correia, H. 2009. 253 - 271Raw material: importance of quality and safety a review. Flavour and Fragrance Journal. 25: 253 - 271.

Sass, C., Little, D. P., Stevenson, D. W., Specht, C. D. 2007. DNA barcoding in the cycadales: testing the potential of proposed barcoding markers for species identification of cycad. PLoS One. 2007;2: e1154

Serino, G. and Maliga, P. 1998. RNA Polymerase Subunits Encoded by the Plastid rpo Genes Are Not Shared with the 
Nucleus-Encoded Plastid Enzyme. Plant Physiol. 117: 1165 - 1170.

Sgamma, T., Lockie-Williams, C., Kreuzer, M., Williams, S., Scheyhing, U., Koch, E., Slater, A. Howard, C. 2017. DNA barcoding for industrial quality assurance. Planta Med. 83: 1117 - 1129.

Shen,Y.J., Zhao, X., Zhao, S. J. 2007. Genetic diversity of Aquilaria spp. based on molecular marker. https://www.ncbi. nlm.nih.gov. Diakses 10 Desember 2020.

Tanaka, S. and Ito, M. 2019. DNA barcoding for identification of agarwood source species using trnL-trnF and matK DNA sequences. Journal of Natura Medicine. 74 (1): 42 50.

Tanaka,S. and Ito,M. 2019. DNA Bar-coding Method for discrimination origin of resin deposition sites of Agarwood using trnLtrnF region and matK region. https://www.ncbi.nlm.nih.gov. Diakses 10 Desember 2020.

Thitikornpong, W., Palanuvej, C, Ruangrungsi, N. 2018. DNA barcoding for authentication of the endangered plants in genus Aquilaria. Thai J Pharm Sci, 42, $214-220$.

Wangiyana, I G. A. S., 2016. Phylogenetic analysis of Aquilaria and Gyrinops member based on trnL-trnF gene sequence of Chloroplast. Jurnal Sangkareang Mataram. 2 (4): $41-46$.

Wangiyana, I G. A. S., Wanitaningsih, S. K., Sanjaya, A. 2018. Bioinduksi Gyrinops versteegii Menggunakan Inokulan Berbahan Baku Medium Tauge dengan Berbagai Kedalaman Pengeboran. Seminar Nasional Implementasi Iptek Pertanian Berkelanjutan yang Tangguh Menuju Kedaulatan Pangan. 1 (1), 144 - 152.

Wangiyana, I G. A. S. and Malik, S. 2018. Application of Arbuscular Mycorrhiza from Senaru Forest Rhizosphere for Gyrinops versteegii Germination and Growth. Biosaintifika. 10 (2): 432 - 438.

Wangiyana, I G. A. S., Triandini, I. G. A. A. H., Putradi, D., Wangiyana, W. 2018. Tannin Concentration of Gyrinops Tea from Leaves of Juvenile and Mature Agarwood Trees (Gyrinops versteegii Gilg (Domke)) with Different Processing Methods. Journal of Chemical and Pharmaceutical Research 10 (10): 113 - 119

Wangiyana, I G. A. S. and Putri, D. S. 2019. Aplikasi Zat Pengatur Tumbuh dan Kegiatan Pruning dalam Optimalisasi
Budidaya Gaharu di Desa Duman Kecamatan Lingsar Lombok Barat. Lumbung Inovasi. 4 (1): 54 - 62.

Wangiyana, I G. A. S., 2019. Similarity analysis of genera Aquilaria and Gyrinops based on vegetative structure feature using different clustering method. Jurnal Sangkareang Mataram. 5 (1): 62 - 68.

Wangiyana, I G. A. S., Wanitaningish, S. K., Anggadhania, L., 2020. Pelatihan Teknologi Bio-induksi untuk Petani Gaharu di Desa Pejaring, Kabupaten Lombok Timur. Agrokreatif: Jurnal Ilmiah Pengabdian Kepada Masyarakat. 6 (1): 36 $-44$.

Wangiyana, I G. A. S., Sanjaya, A., Anggadhania, L. 2020. Pengolahan Sampah Buah dan Sayur dari Pasar Induk Mandalika Kota Mataram Nusa Tenggara Barat Sebagai Media Tumbuh Fusarium sp Inokulan Gaharu. IJEEM-Indonesian Journal of Environmental Education and Management. 5 (2): 173 - 183.

White, T. J., Bruns, T., Lee, S., Taylor, J. 1990. Amplification and direct sequencing of fungal ribosomal RNA genes for phylogenetics. Innis, M. A., Gelfand, D. H., Sninsky J. J., White, T. J. editors. PCR protocols-a guide to methods and applications. New York: Academic Press: $315-322$.

Win, N. W., Hanyuda, T., Arai, S., Uchimura, M., 2008. Three new records of Padina in Japan based on morphological and molecular markers. Physiological Research. 56 (4): $288-300$.

Yu, J., Yan, H., Lu, Z., Zhou, Z. 2011. Screening potential DNA barcode regions of chloroplast coding genome for Citrus and its related genera. Scientia Agricultura Sinica. 44: $341-348$.

Zahra, N. B., Shinwari, Z. K., Qaiser, M. 2016. DNA Barcoding: A Tool for Standardization of Herbal Medicinal Products (Hmps) Of Lamiaceae From Pakistan. Pakistan Journal of Botany 48 (5): 2167 - 2174. 